\title{
Benzotropolone moiety in theaflavins is responsible for inhibiting peptide- transport and activating AMP-activated protein kinase in Caco-2 cells
}

\author{
Ha-Young Park, Yuri Kunitake, and Toshiro Matsui*
}

Department of Bioscience and Biotechnology, Division of Bioresources and Biosciences, Faculty of Agriculture, Graduate School of Kyushu University, 6-10-1 Hakozaki, Fukuoka, 812-8581, Japan

*Corresponding Author: Toshiro Matsui, PhD, Professor, Department of Bioscience and Biotechnology, Division of Bioresources and Biosciences, Faculty of Agriculture, Graduate School of Kyushu University, 6-10-1 Hakozaki, Fukuoka, 812-8581, Japan

Submission date: April 23, 2013; Acceptance date: May 23, 2013; Publication date: May 24, 2013

\section{ABSTRACT}

Objective: In the small intestine, peptide transporter 1 (PEPT1) plays a role in the transport of di- and tri-peptides. Recently, we found that theaflavins (TFs), dimeric catechins, inhibited the transport of di-peptides across Caco- 2 monolayers by suppressing the expression of PEPT1 through AMP-activated protein kinase (AMPK) activation. In this study, we investigated the structural requirement of theaflavins for the effect, and the mechanism(s) underling theaflavin-induced AMPK activation.

Methods: Theaflavin-3'-O-gallate (TF3'G) was used for this study, since it possessed the most potent inhibition power for peptide-transport among theaflavins. Absorption ability was measured with Caco-2 cell monolayers treated with or without $20 \mu \mathrm{M}$ sample (TF3' $\mathrm{G}$ or its related compounds) in an Ussing Chamber. The amount of Gly-Sar (a model of PEPT1transporing peptide) transport at fixed time-points to $60 \mathrm{~min}$ was determined by fluorescent naphthalene-2,3-dicarboxaldehyde-derivatized assay (Ex/Em: $405 \mathrm{~nm} / 460 \mathrm{~nm}$ ). The apparent permeability coefficient $\left(\mathrm{P}_{\mathrm{app}}\right)$ was used to evaluate the permeability. Expression of PEPT1 protein in Caco-2 cells treated with or without $20 \mu \mathrm{M}$ TF3' $\mathrm{G}$ in the presence or absence of inhibitor (10 $\mu \mathrm{M}$ compound $\mathrm{C}$ as AMPK inhibitor or $25 \mu \mathrm{M}$ STO-609 as CaMKK inhibitor) was evaluated by Western blot.

Results: The $\mathrm{P}_{\mathrm{app}}$ value of Gly-Sar significantly $(P<0.05)$ decreased in $20 \mu \mathrm{M}$ purprogallintreated Caco-2 cells as well as in TF3'G-treated cells, together with the reduction of PEPT1 expression, while their monomeric catechins did not show any $\mathrm{P}_{\text {app }}$ reduction. In TF3' $\mathrm{G}-$ treated Caco- 2 cells, the recovery of the reduced PEPT1 expression was found by $10 \mu \mathrm{M}$ compound C, but not STO-609.

Conclusion: The study demonstrated that the benzotropolone moiety in theaflavins was a 
crucial structural requirement for exerting the inhibition of intestinal peptide-transport, and the suppression of PEPT1 expression by theaflavins would be caused by activating LKB1/AMPK pathway, but not CaMKK/AMPK pathway.

Keywords: Theaflavin-3'-O-gallate, Peptide transport, PEPT1, Benzotropolone, AMPactivated protein kinase, Calmodulin-dependent protein kinase kinase

\section{BACKGROUND:}

To date, many food scientists have paid attention to physiological functions of small peptides in the body, some of which have been proven to be effective for the prevention of life-style related diseases such as hypertension [1,2], hypercholesterolemia [3] and inflammation [4]. Previous researches provided the health-benefit of peptide intake that can be absorbed via intestinal peptide transporter 1 (PEPT1) [5].

PEPT1 that is expressed as peptide transporter in the intestinal membrane can recognize diand tri-peptide lengths $[5,6]$. In intestinal membranes it has been reported that the expression of PEPT1 was closely associated with AMP-activated protein kinase (AMPK, a serine/threonine kinase) activation [7, 8]. Pieri et al. demonstrated that the activated AMPK resulted in a decrease of peptide absorption, along with the suppression of PEPT1 proteins in Caco-2 cells [7]. In our previous report, we also found that the transport of di-peptides across Caco-2 monolayers was markedly inhibited by theaflavin-induced AMPK activation [9]. So far, although it has been reported that catechins [10] and epigallocatechin-3-gallate [11] could stimulate AMPK activity in the liver, no study was found for AMPK activation by condensed catechins or theaflavins in the intestine. In addition, involvement(s) of up-streamed kinases including liver kinase $\mathrm{B} 1$ (LKB1) and $\mathrm{Ca}^{2+} /$ calmodulin-dependent protein kinase kinase (CaMKK) on the theaflavin-induced AMPK activation still remains unclear.

In this study, we investigated the structural requirement of theaflavins for the inhibition of intestinal peptide-transport in Caco-2 cells, and clarified whether LKB1/ or CaMKK/AMPK was involved in theaflavin-induced AMPK activation. We used theaflavin-3'-O-gallate (TF3'G) throughout this study, since it possessed the most potent inhibition power for peptide-transport among theaflavins [9].

\section{MATERIALS AND METHODS:}

Reagents: Dulbecco's modified Eagle's medium (DMEM) and fetal bovine serum (FBS) were purchased from GIBCO Life Technologies (Grand Island, NY, USA). Dimethylsulfoxide (DMSO) was obtained from Sigma-Aldrich (St. Louis, MO, USA). Seeding basal medium, enterocyte differentiation medium and MITO+TM serum extender for Caco-2 cell culture were purchased from BD Biosciences (Franklin Lakes, NJ, USA). (-)Epigallocatechin (EGC), (-)-epicatechin gallate (ECG), (-)-epigallocatechin gallate (EGCG), (-)-epicatechin (EC) and TF3'G were products of Nacalai Tesque Company (Kyoto, Japan). Purpurogallin with a benzotropolone ring was purchased from Pfaltz \& Bauer Inc. (Waterbury, CT, USA). Glycyl-sarcosine (Gly-Sar, a model peptide for PEPT1 transport [12]) was obtained from Kokusan Chemical Company. (Tokyo, Japan). Naphthalene-2,3dialdehyde (NDA), compound C and STO-609 were purchased from Nacalai Tesque. All other reagents were of analytical grade and used without further purification. 
Caco-2 cell culture: Caco- 2 cells were cultured under standard cell culture conditions as described previously [9]. Caco-2 cells used in this study were between passages 50 and 60 . For transport studies, cells were grown on a BD Falcon ${ }^{\mathrm{TM}}$ cell culture insert (PET membrane, $0.9 \mathrm{~cm}^{2}, 1.0 \mu \mathrm{m}$ pore size; BD Biosciences, Bedford, MA, USA) coated with type I collagen (collagen gel culturing kit, Cellmatrix type I-A, Nitta Gelatin, Osaka, Japan). The cells were seeded at a density of $4.0 \times 10^{5}$ cells $/ \mathrm{mL}$ and cultured in a seeding basal medium containing MITO+TM serum extender for $48 \mathrm{~h}$. After the medium was replaced with an enterocyte differentiation medium containing MITO ${ }^{+\mathrm{TM}}$ serum extender, cells were incubated for another 72 hours to form monolayers. The medium was freshly changed every 24 hours. The integrity of Caco-2 monolayers was evaluated by measuring the transepithelial electrical resistance (TEER) with a multi-channel EVC-4000 system (World Precision Instruments, FL, USA). Monolayers with TEER values of $>100 \Omega \mathrm{cm}^{2}$ were used for peptide-transport experiments.

Cell treatment: Treatment of Caco-2 cell monolayers with sample (TF3'G or its related compounds) were performed by replacing 10\% FBS in DMEM with the medium containing $20 \mu \mathrm{M}$ sample and allowing them to incubate for 24 hours at $37{ }^{\circ} \mathrm{C}$ at $\mathrm{O}_{2}: \mathrm{CO}_{2}$ (95:5). Cells incubated in sample-free medium were used as a control. The medium containing the sample was prepared by diluting a stock solution of each sample, dissolved in DMSO, with $10 \%$ FBS in DMEM. The final concentration of DMSO was $0.5 \%$ throughout the experiments to avoid any cell damage by DMSO [13].

Transport study: Transport experiments in Caco-2 cell monolayers were performed using an Ussing Chamber system (Model U-2500; Warner Instrument Co., Hamden, CT, USA). Caco2 cell monolayers grown in transwell inserts were gently rinsed with Hanks' balanced salt solution (HBSS) buffer ( $\mathrm{pH}$ 6.0) to wash or remove any free samples in the medium, and carefully mounted in the Ussing Chamber using blunt forceps. An aliquot $(7.5 \mathrm{~mL})$ of HBSS buffer (adjusted to $\mathrm{pH} 6.0$ with $10 \mathrm{mM}$ MES [2-( $N$-morpholino) ethanesulfonic acid]) or HBSS buffer (adjusted to $\mathrm{pH} 7.4$ with $10 \mathrm{mM}$ HEPES [4-(2-hydroxyethyl)-1-piperazine ethanesulfonic acid]) was added to the apical or basolateral side, respectively. After equilibration for $15 \mathrm{~min}$ at $37{ }^{\circ} \mathrm{C}$, the transport experiments were started by replacing the apical buffer with fresh HBSS buffer ( $\mathrm{pH}$ 6.0) containing $10 \mathrm{mM}$ Gly-Sar for Caco-2 cells treated with or without $20 \mu \mathrm{M}$ sample. During the experiments, solutions on both sides were bubbled continuously with a mixture of $\mathrm{O}_{2}: \mathrm{CO}_{2}$ (95:5). Aliquots $(0.2 \mathrm{~mL}$ each) of solution were drawn from the basolateral side at time intervals of 15, 30, 45 and 60 minutes to determine the amount of transported Gly-Sar. The same volume of fresh buffer was added to the basolateral side at each time point. The membrane barrier and transport ability of cells were maintained during the 60 min-transport experiments without any reduction of TEER value ( $>100 \Omega \mathrm{cm}^{2}$ ) by Gly-Sar. The amount of Gly-Sar transported to the basolateral side was determined by a fluorescent NDA-derivatization method [14]. Briefly, $10 \mu \mathrm{L}$ of $20 \mathrm{mM}$ sodium cyanide in borate buffer $(\mathrm{pH}$ 9.5) was added to the basolateral solution taken at each time point $(100 \mu \mathrm{L})$ in a 96-well microplate, followed by the addition of $50 \mu \mathrm{L}$ of $0.1 \mathrm{mM}$ NDA solution in methanol. After incubating at $25^{\circ} \mathrm{C}$ for $60 \mathrm{~min}$, the fluorescence intensity of NDA-Gly-Sar was measured using a fluorescence spectrophotometer (Wallac ARVO ${ }^{\mathrm{TM}} \mathrm{SX}$ 1420 Multilabel Counter, Perkin-Elmer Life Sciences, Tokyo, Japan) at an excitation wavelength of $405 \mathrm{~nm}$ and emission wavelength of $460 \mathrm{~nm}$. In addition, the fluorescence 
intensity of basolateral solution taken at each time point for blank (no Gly-Sar) transport experiments was used to cancel an increase in intensity by any contaminants from Caco-2 cells.

The apparent permeability coefficient $\left(\mathrm{P}_{\mathrm{app}}\right)$ was calculated from the following equation:

$$
\mathrm{P}_{\mathrm{app}}(\mathrm{cm} / \mathrm{s})=\frac{V}{A C_{0}} \frac{d C}{d t}
$$

$d C / d t$ is the change in concentration at the basolateral side over time ( $\mathrm{mmol} / \mathrm{s}), V$ is the volume of solution in the basolateral compartment $(7.5 \mathrm{~mL}), A$ is the surface area of the membrane $\left(0.2826 \mathrm{~cm}^{2}\right)$ and $C_{0}$ is the initial concentration at the apical side (mmol). The effect of sample (TF3' $\mathrm{G}$ or its related compounds) on $\mathrm{P}_{\text {app }}$ was expressed relative to control $(\%)$.

Protein extraction and Western blotting: Expression of PEPT1 protein in Caco-2 cells treated with or without TF3' $\mathrm{G}(20 \mu \mathrm{M})$ in the presence or absence of inhibitor $(10 \mu \mathrm{M}$ compound $\mathrm{C}$ as AMPK inhibitor or $25 \mu \mathrm{M}$ STO-609 as CaMKK inhibitor) for $24 \mathrm{~h}$ at $37{ }^{\circ} \mathrm{C}$ was evaluated by Western blot analysis. Briefly, protein $(1.3 \mathrm{mg} / \mathrm{mL})$ extracted from Caco-2 cells using radioimmunoprecipitation assay buffer was mixed with an equal volume of sample buffer (20\% glycerol, $4 \%$ sodium dodecylsulfate, 3\% dithiothreitol, $0.002 \%$ bromophenol blue and $0.125 \mathrm{M}$ Tris- $\mathrm{HCl}, \mathrm{pH} 6.8$ ) and boiling in the water for $5 \mathrm{~min}$. An aliquot $(9.75 \mu \mathrm{g})$ of the prepared sample was applied to $10 \%$ SDS polyacrylamide gel electrophoresis for $2 \mathrm{~h}$ at $20 \mathrm{~mA}$ and transferred onto PVDF membrane (Hybond-P, GE Healthcare, Piscataway, NJ, USA) for $1.5 \mathrm{~h}$ at $40 \mathrm{~mA}$. The membrane was blocked with $5 \%$ non-fat dried milk in TBS-T (Tris-buffered saline containing $0.05 \%$ Tween 20) for $1 \mathrm{~h}$ at room temperature and then probed with the primary antibody for PEPT1 or $\beta$-actin, followed by rabbit anti PEPT1 antibody (1:1000, Abbiotec, San Diego, CA, USA) or mouse anti $\beta$ actin antibody (1:1000, Applied biological materials inc, Richmond, BC, Canada) overnight at $4{ }^{\circ} \mathrm{C}$. The membrane was then re-probed with HRP-conjugated donkey anti-rabbit IgG antibody or HRP-conjugated sheep anti-mouse IgG antibody (1:1000, GE Healthcare, Buckinghamshire, UK) for $1 \mathrm{~h}$ at room temperature. The membrane was detected with ECL plus detection reagent using an ImageQuant LAS 4000 (GE Healthcare, Piscataway, NY, USA)). Quantitation of PEPT1 and $\beta$-actin were performed with ImageQuant TL 7.0 software (GE Healthcare), and the PEPT1 protein levels in Caco-2 cells treated with TF3'G or TF3'G in the presence or absence of inhibitor were expressed relative to the control (or TF3'Guntreated cells).

Statistical analysis: Results are expressed as the mean \pm SEM. The statistical significance between groups was analyzed using one-way ANOVA followed by Tukey-Kramer's $t$-test for post hoc analysis. $P<0.05$ was considered to be significant. Statistical analyses were conducted with StatView J5.0 (SAS Institute Inc., Cary, NC, USA).

RESULTS and DISCUSSION: Theaflavins rich in black tea [15] are a group of condensed polyphenols. Recently, many researchers have reported their physiological functions such as anti-inflammatory [16], antioxidant [16, 17] and anti-hyperglycemic activities [18]. Lorenz et $a l$. also revealed their ex vivo functions regarding vasorelaxation and promoting nitric oxide 
(NO) in aorta [19]. However, as we have clearly demonstrated in our previous report [9], theaflavins themselves were not a penetrant through intestinal membrane, irrespective of the above-mentioned health-benefits. In addition, we also demonstrated that non-absorbable theaflavins had potency in inhibiting intestinal peptide-transport [9], whereas no further useful structural information and underlying mechanism(s) of theaflavin-induced inhibition of peptide-transport was obtained.

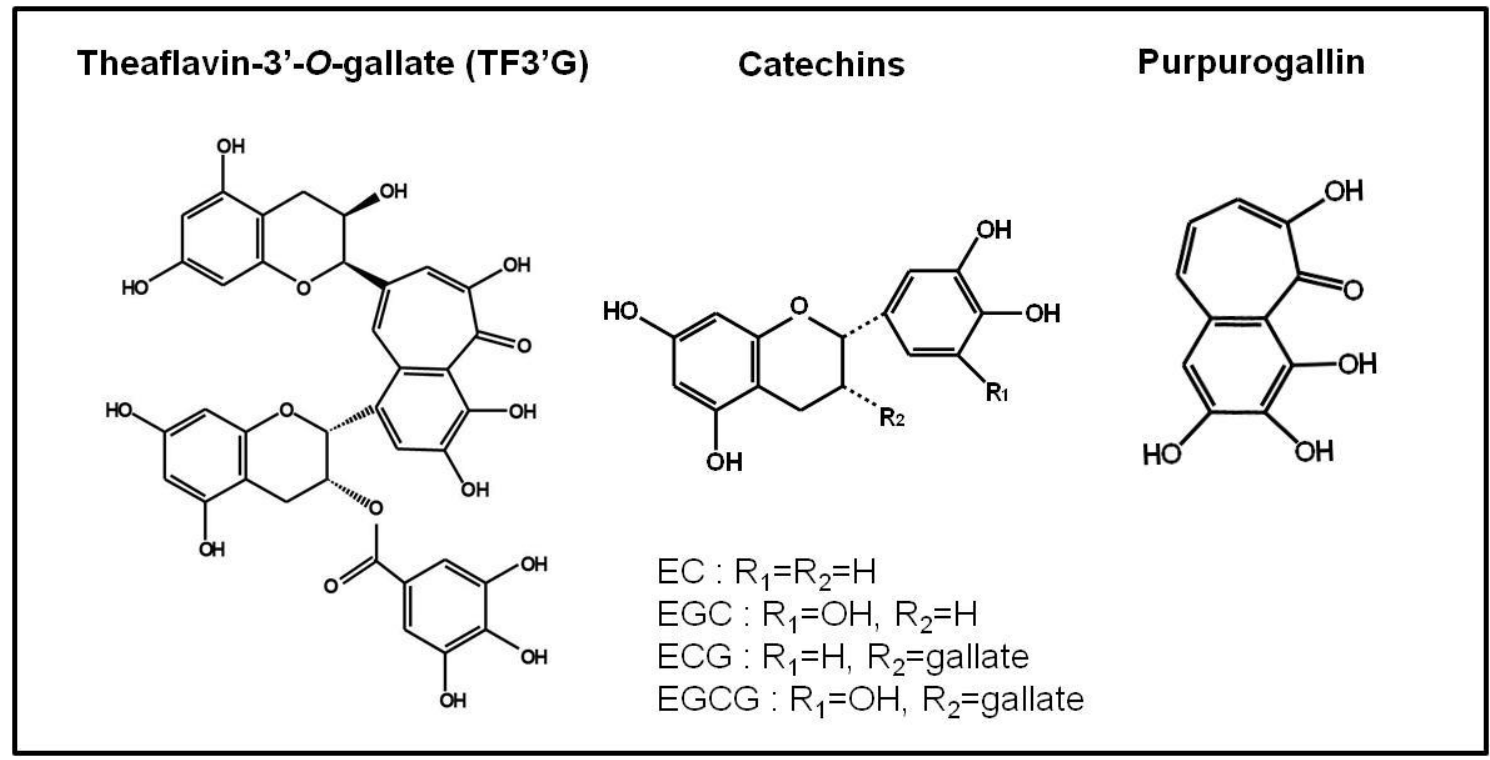

Fig. 1. Chemical structures of theaflavin-3'-O-gallate (TF3' $\mathrm{G})$, catechins and purpurogallin used in this study

Effect of TF3'G and its related compounds on Gly-Sar transport across Caco-2 cell monolayers: In order to get information on structural requirement of TFs exerting peptidetransport inhibition, compounds related to TF3'G skeleton as shown in Fig. 1 were used for Gly-Sar transport experiments across Caco-2 monolayers. As shown in Fig 2, four catechin monomers did not show any significant $\mathrm{P}_{\text {app }}$ reduction in Caco- 2 cells, while the $\mathrm{P}_{\text {app }}$ of GlySar was significantly $(P<0.05)$ reduced in $20 \mu \mathrm{M}$ purprogallin-treated cells as similar to TF3'G treated cells (TF3'G, 41\%; purprogallin, 30\% of control in $\mathrm{P}_{\text {app }}$ ). This clearly demonstrated that the benzotropolone moiety in theaflavins, which has a characteristic 7-ring structure [20], was a crucial structural requirement for exerting the inhibition of intestinal peptide-transport in Caco- 2 cells.

Effect of AMPK inhibition on PEPT1 protein expression in TF3'G-treated Caco-2 cells: Effect of compound $\mathrm{C}$, a specific inhibitor of AMPK, on PEPT1 protein expression in Caco-2 cells treated with $20 \mu \mathrm{M}$ TF3'G was evaluated by Western blot analysis. As shown in Fig. 3, $20 \square \mathrm{M} \mathrm{TF3}$ ' $\mathrm{G}$ treatment for Caco-2 cells resulted in a significant reduction of PEPT1 expression. In contrast, the recovery of the expression by $10 \mu \mathrm{M}$ compound $\mathrm{C}$ in TF3'Gtreated Caco-2 cells revealed that the reduction of PEPT1 expression by TF3'G was responsible for AMPK activation. The result was in good agreement with our previous report [9], in which the reducing transport of Gly-Sar in TF3'G-treated Caco-2 cells was abolished by compound $\mathrm{C}$. 


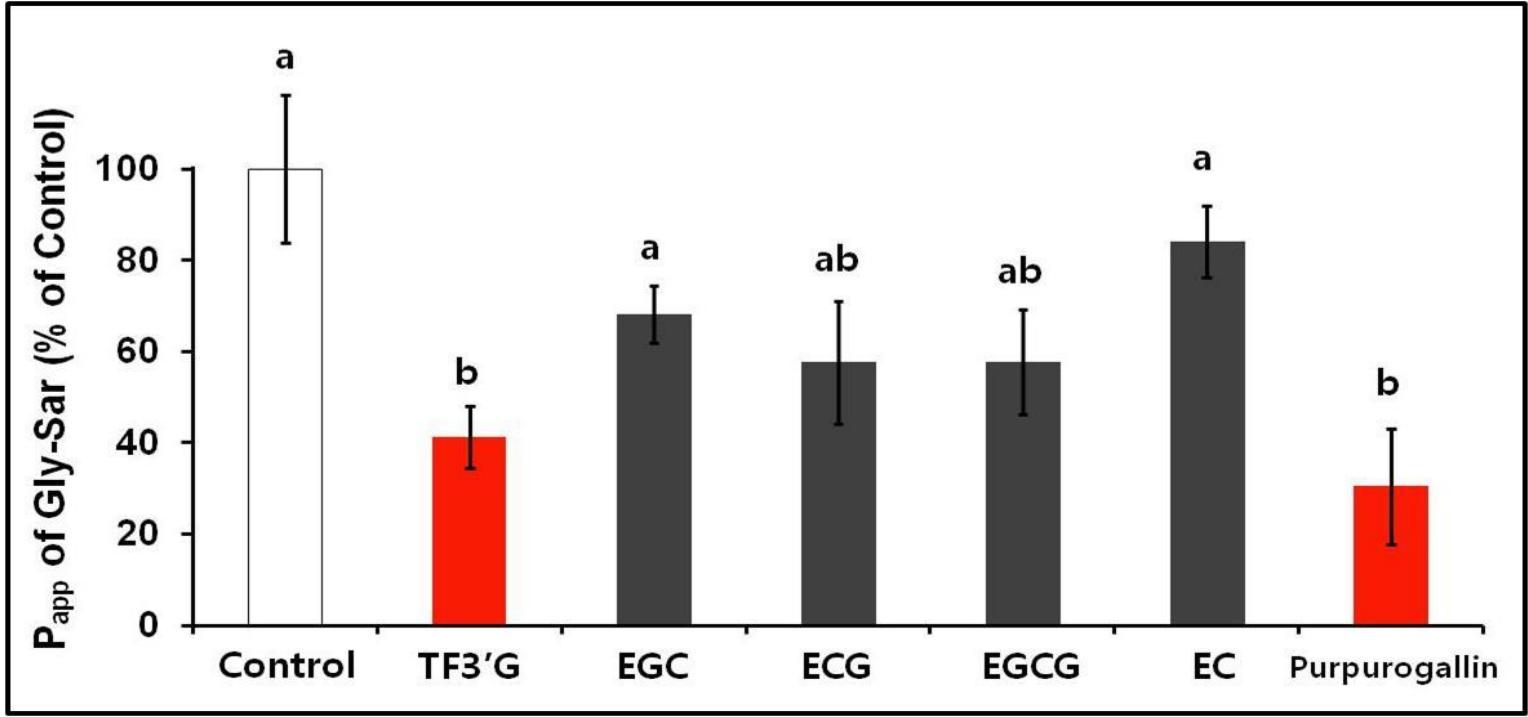

Fig. 2. Effect of theaflavin-3'- $O$-gallate and its related compounds on Gly-Sar transport. Caco-2 cells were treated with $20 \mu \mathrm{M}$ sample for $24 \mathrm{~h}$. Theaflavin-3'-O-gallate, TF3'G; (-)epigallocatechin, EGC; (-)-epicatechin gallate, ECG; (-)-epigallocatechin gallate, EGCG; (-)epicatechin, EC. Control: transport of Gly-Sar in Caco-2 cells without TF3'G treatment. The values (relative $\mathrm{P}_{\text {app }}$ value vs. control, \%) are expressed as the mean \pm SEM ( $\left.\mathrm{n}=3-5\right)$. Means without a common letter are significantly different; $P<0.05$. Significant difference between groups was evaluated by Tukey-Kramer's $t$-test.

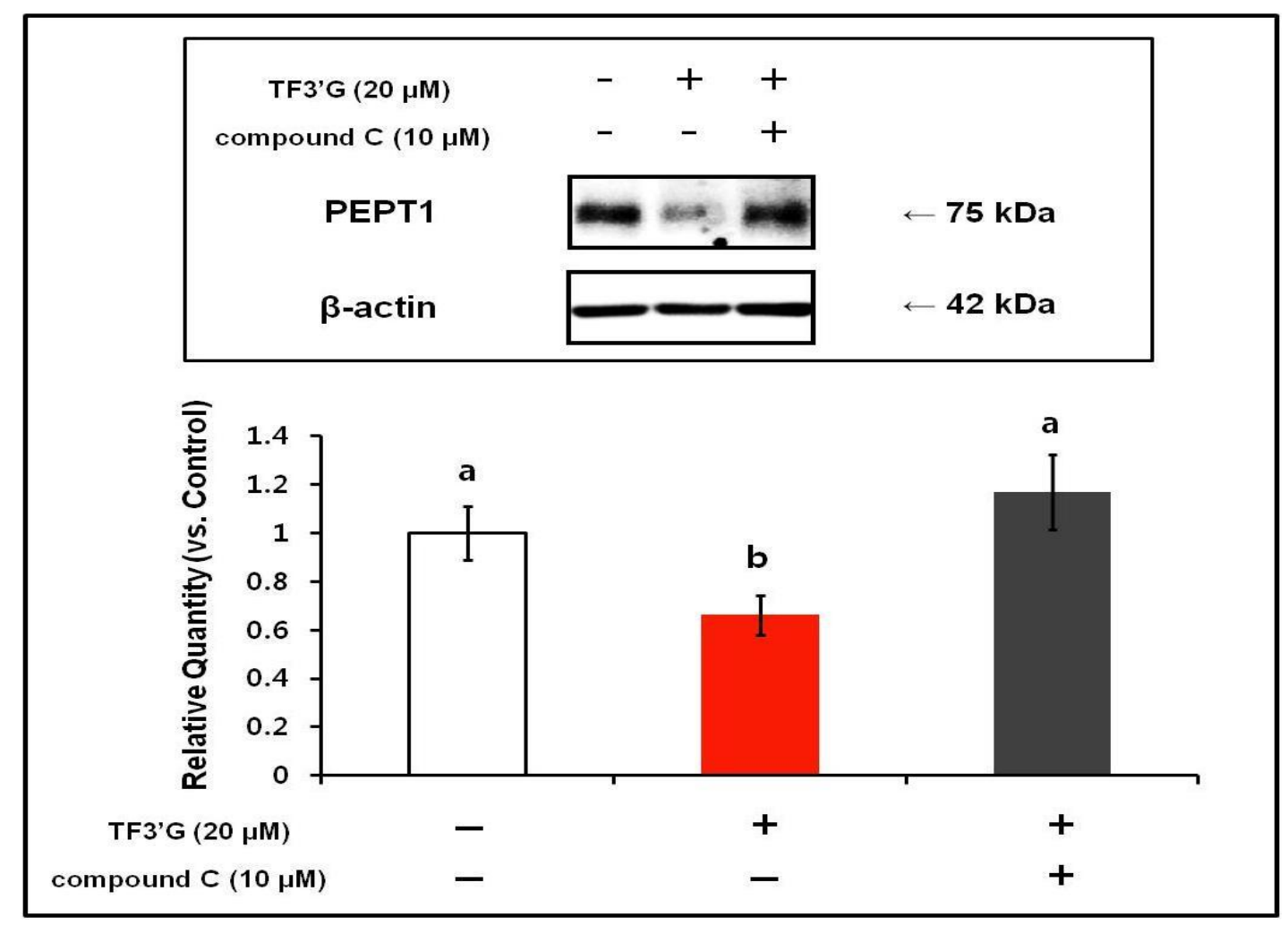

Fig. 3. Effect of AMPK inhibition on PEPT1 protein expression in Caco-2 cells treated with theaflavin-3'-O $\mathbf{O}$-gallate. $\mathrm{Caco}-2$ cells were treated with $20 \mu \mathrm{M}$ theaflavin-3'- $O$-gallate $\left(\mathrm{TF}^{\prime} \mathrm{G}\right)$ in the presence or absence of $10 \mu \mathrm{M}$ compound $\mathrm{C}$. Values are expressed as the mean \pm SEM $(\mathrm{n}=3)$. Means without a common letter are significantly different; $\mathrm{P}<0.05$. Significant difference between groups was evaluated by Tukey-Kramer's $t$-test. 
Effect of CaMKK inhibition on PEPT1 protein expression in TF3'G-treated Caco-2 cells: Effect of STO-609, a selective inhibitor of CaMKK, on PEPT1 protein expression in Caco- 2 cells treated with $20 \mu \mathrm{M}$ TF3'G was evaluated by Western blot analysis. As shown in Fig. 4, no significant recovery of the reduced PEPT1 expression by STO-609 was obtained in the TF3'G-treated Caco-2 cells. This result clearly suggested that the CaMKK-activated AMPK pathway [11, 21-22] could be excluded from the mechanism(s) underlying TF3'Ginduced PEPT1 suppression.

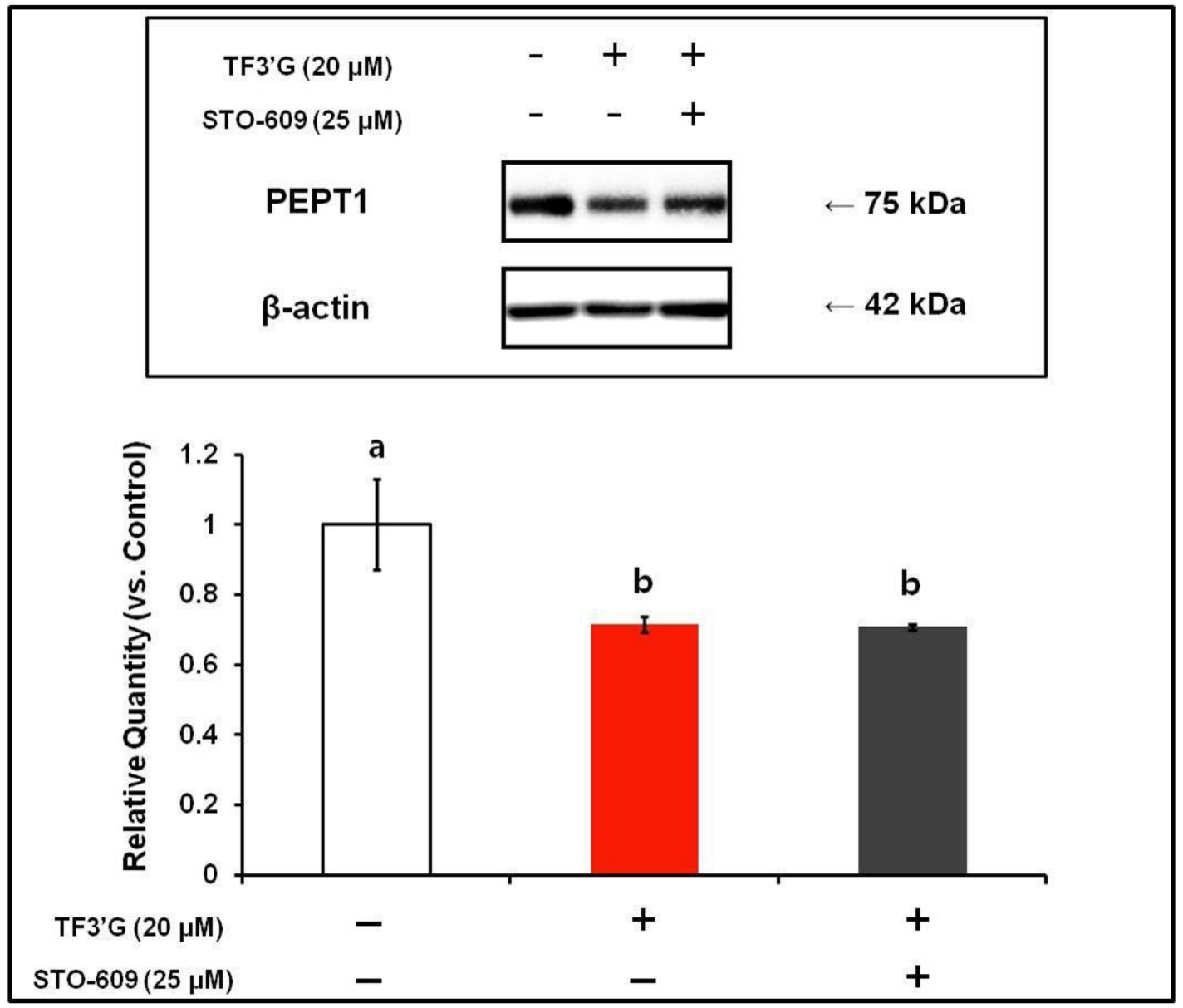

Fig. 4. Effect of CaMKK inhibition on PEPT1 protein expression in Caco-2 cells treated with theaflavin-3'-O-gallate. $\mathrm{Caco}-2$ cells were treated with $20 \mu \mathrm{M}$ theaflavin-3'-O-gallate (TF3' $\mathrm{G}$ ) in the presence or absence of $25 \mu \mathrm{M}$ STO-609. Values are expressed as the mean \pm SEM $(\mathrm{n}=3)$. Means without a common letter are significantly different; $P<0.05$. Significant difference between groups was evaluated by Tukey-Kramer's $t$-test.

There have been some reports on the potential of polyphenols in the activation of CaMKK/AMPK signaling pathway $[8,11,20]$. Collins et al. reported that EGCG reduced hepatic gluconeogenesis by activating CaMKK/AMPK pathway [11]. However, in this study, we demonstrated that TF3'G was not involved in the CAMKK/AMPK pathway, since STO609, a CaMKK inhibitor, did not alter the reduced PEPT1 expression by TF3'G (Fig. 4). It has been reported that AMPK phosphorylation in tissues mainly concerned either the activation of CaMKK or LKB1 signaling pathway $[8,11,20]$. Therefore, the finding in Fig. 4 suggested the possible involvement of theaflavins in the activation of LKB1/AMPK signaling pathway, but not CaMKK/AMPK. However, further experiments using LKB1-knocked down cells must be required to make clear the route activated by theaflavins in Caco-2 cells. 


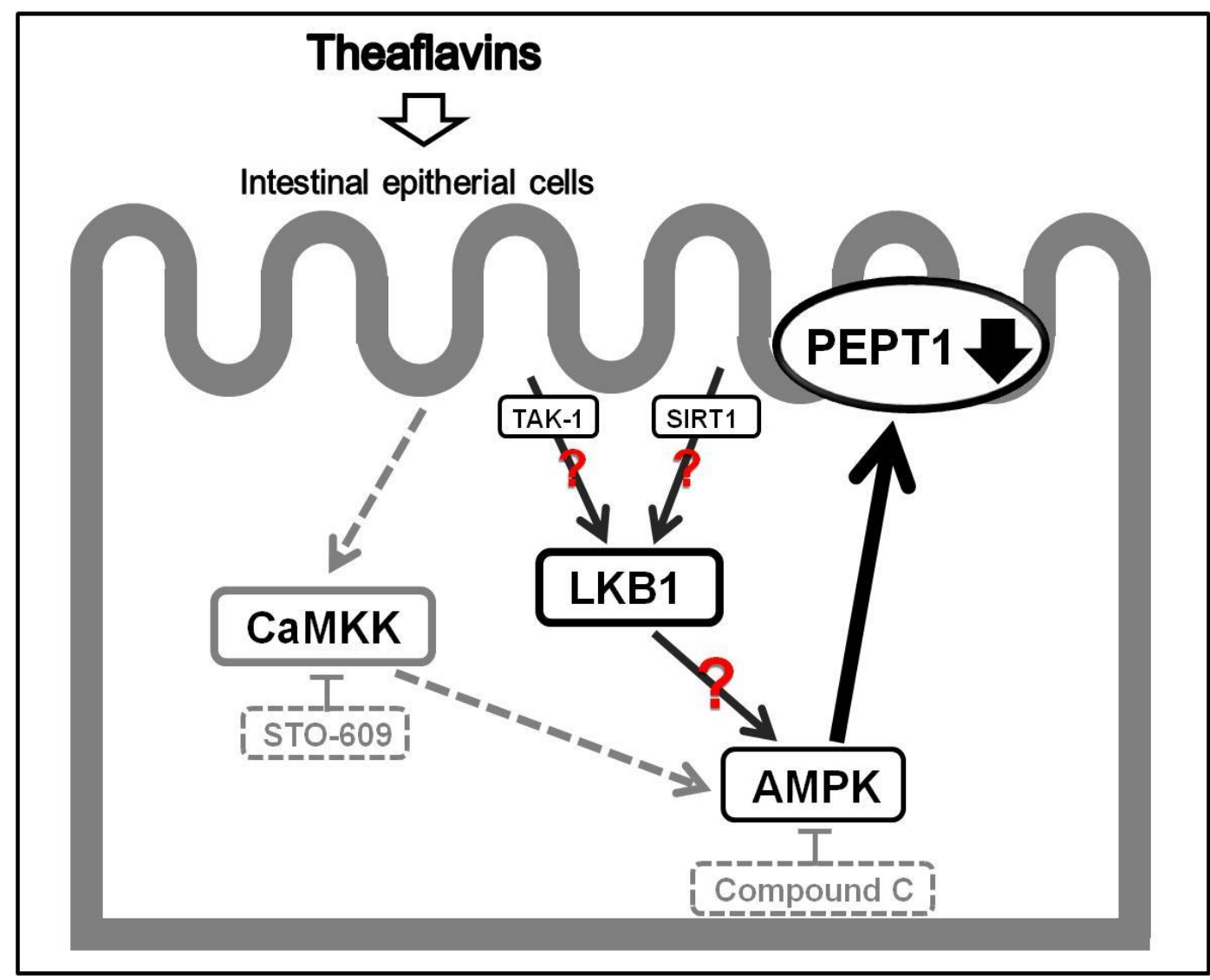

Fig. 5. Proposed upstream mechanism(s) of theaflavins on signaling pathway in Caco-2 cells.

As summarized in Fig. 5, the present findings suggested that theaflavins may stimulate LKB1/AMPK signaling so as to suppress PEPT1 expression in Caco-2 cells, although mechanisms underlying LKB1 activation by either transforming growth factor- $\beta$-activated kinase (TAK-1) [23-25] or Sirtuin 1 (SIRT1) [26, 27] in Caco-2 cells remain unclear. So far, Lin et al. [28] have reported that in HepG2 cell experiments theaflavins could accumulate hepatic lipids by activating LKB1/AMPK pathway. Considering the report and the expression of LKB1 in Caco-2 cells [29], we can speculate the possible role of theaflavins in the LKB1/AMPK signaling pathway to suppress PEPT1 expression in intestinal membrane. In addition, there might be specific receptor(s) that recognizes theaflavins or benzotropolone ring in Caco-2 cells, and experiments for binding of theaflavins to intestinal membrane are now in progress.

\section{CONCLUSIONS:}

We demonstrated that the benzotropolone moiety in theaflavins, which has a characteristic 7ring structure, was a crucial structural requirement for exerting the inhibition of intestinal peptide-transport in Caco-2 cells. It seems likely that theaflavins may act as an activator for LKB1/AMPK pathway, but not CaMKK/AMPK pathway, to suppress PEPT1 expression.

Abbreviations: PEPT1, peptide transporter 1; AMPK, AMP-activated protein kinase; LKB1, liver kinase B1; CaMKK, calmodulin-dependent protein kinase kinase; TF3'G, theaflavin-3'$O$-gallate; NDA, naphthalene-2,3-dialdehyde; TEER, transepithelial electrical resistance; $\mathrm{P}_{\text {app }}$, apparent permeability coefficient; TAK-1, either transforming growth factor- $\beta$-activated 
kinase; SIRT1, sirtuin 1

Competing interests: There were no competing interests.

Authors' contributions: All authors have been contributed

Acknowledgements and funding: This study was in part supported by a Grant-in-aid for the Ministry of Education, Science, Sports and Culture of Japan (No. 22248014) to TM. The authors thank Junko Takeda in Kyushu University for her kind technical supports.

\section{REFERENCES:}

1. Matsui T, Matsumoto K: Antihypertensive peptides from natural resources. Advances in Phytomedicine 2006, 2:255-271.

2. Kawasaki T, Seki E, Osajima K, Yoshida M, Asada K, Matsui T, Osajima Y: Antihypertensive effect of valyl-tyrosine, a short chain peptide derived from sardine muscle hydrolyzate, on mild hypertensive subjects. J Hum Hypertens 2000, 14: 519 523.

3. Nagaoka S, Futamura Y, Miwa K, Awano T, Yamauchi K, Kanamaru Y, Tadashi K, Kuwata T: Identification of novel hypocholesterolemic peptides derived from bovine. Biochem Biophys Res Commun 2001, 281:11-17.

4. Wang YF, Xu X, Fan X, Zhang C, Wei Q, Wang X, Guo W, Xing W, Yu J, Yan JL, Liang HP: A Cell-penetrating peptide suppresses inflammation by inhibiting NF- $\kappa B$ signaling. Mol Ther 2011, 12:1849-1857.

5. Shiraga T, Miyamoto K, Tanaka H, Yamamoto H, Taketani Y, Morita K, Tamai I, Tsuji A, Takeda E: Cellular and molecular mechanisms of dietary regulation on rat intestinal $\mathrm{H}^{+} /$Peptide transporter PepT1. Gastroenterology 1999, 116:354-62.

6. Fei YJ, Kanai Y, Nussberger S, Ganapathy V, Leibach FH, Romero MF, Singh SK, Boron WF, Hediger MA: Expression cloning of a mammalian proton-coupled oligopeptide transporter. Nature 1994, 368:563-566.

7. Pieri M, Christian HC, Wilkins RJ, Boyd CA, Meredith D: The apical (hPepT1) and basolateral peptide transport systems of Caco-2 cells are regulated by AMP-activated protein kinase. Am J Physiol Gastrointest Liver Physiol 2010, 299:G136-143.

8. Hallows KR: Emerging role of AMP-activated protein kinase in coupling membrane transport to cellular metabolism. Curr Opin Nephrol Hypertens 2005, 14:464-471.

9. Takeda J, Park HY, Kunitake Y, Yoshiura K, Matsui T: Theaflavins, dimeric catechins, inhibit peptide transport across Caco-2 cell monolayers via downregulation of AMP-activated protein kinase-mediated peptide transporter PEPT1. Food Chem 2013, 138: 2140-2145.

10. Murase T, Misawa K, Haramizu S, Hase T: Catechin-induced activation of the LKB1/AMP-activated protein kinase pathway. Biochem Pharmacol 2009, 78:78-84.

11. Collins QF, Liu HY, Pi J, Liu Z, Quon MJ, Cao W: Epigallocatechin-3-gallate (EGCG), a green tea polyphenol, suppresses hepatic gluconeogenesis through 5'AMP-activated protein kinase. J Biol Chem 2007, 282:30143-30149.

12. Adibi SA: Regulation of expression of the intestinal oligopeptide transporter (pept-1) in health and disease. Am J Physiol Gastrointest Liver Physiol 2003, 285:G779-788. 
13. Da Violante G, Zerrouk N, Richard I, Provot G, Chaumeil JC, Arnaud P: Evaluation of the cytotoxicity effect of dimethyl sulfoxide (DMSO) on Caco2/TC7 colon tumor cell cultures. Biol Pham Bull 2002, 25:1600-1603.

14. Ueno T, Tanaka M, Matsui T, Matsumoto K: Determination of antihypertensive small peptides, Val-Tyr and Ile-Val-Tyr, by fluorometric high-performance liquid chromatography combined with a double heart-cut column-switching technique. Anal Sci 2005, 21:997-1000.

15. Krishnan R, Maru GB: Inhibitory effect(s) of polymeric black tea polyphenols on the formation of B(a)P-derived DNA adducts in mouse skin. J Environ Pathol Toxicol Oncol 2005, 24:79-90.

16. Sang S, Lambert JD, Tian S, Hong J, Hou Z, Ryu JH, Stark RE, Rosen RT, Huang MT, Yang CS, Ho CT: Enzymatic synthesis of tea theaflavin derivatives and their anti-inflammatory and cytotoxic activities. Bioorg Med Chem 2004, 12:459-467.

17. Leung LK, Su Y, Chen R, Zhang Z, Huang Y, Chen ZY: Theaflavins in black tea and catechins in green tea are equally effective antioxidants. J Nutr 2001, 131:2248-2251.

18. Tanaka T, Inoue K, Betsumiya Y, Mine C, Kouno I: Two types of oxidative dimerization of the black tea polyphenol theaflavin. J Agric Food Chem 2001, 49:5785-5789.

19. Huang Y, Zhang A, Lau CW, Chen ZY: Vasorelaxant effects of purified green tea epicatechin derivatives in rat mesenteric artery. Life Sci 1998, 63:275-283.

20. Wang C. and Li Y: Research progress on property and application of theaflavins. Am J Biotechnol 2006, 5:213-218.

21. Gormand A, Henriksson E, Ström K, Jensen TE, Sakamoto K, Göransson O: Regulation of AMP-activated protein kinase by LKB1 and CaMKK in adipocytes. J Cell Biochem 2011, 112:1364-1375.

22. Towler MC, Hardie DG: AMP-activated protein kinase in metabolic control and insulin signaling. Circ Res 2007, 100:328-341.

23. Momcilovic M, Hong SP, Carlson M: Mammalian TAK1 activates Snf1 protein kinase in yeast and phosphorylates AMP-activated protein kinase in vitro. J Biol Chem 2006, 281:25336-25343.

24. Chen A, Davis BH, Sitrin MD, Brasitus TA, Bissonnette M: Transforming growth factor-beta 1 signaling contributes to Caco-2 cell growth inhibition induced by 1,25(OH $)_{2} \mathrm{D}_{3}$. Am J Physiol Gastrointest Liver Physiol 2002, 283: G864-874.

25. Xie M, Zhang D, Dyck JR, Li Y, Zhang H, Morishima M, Mann DL, Taffet GE, Baldini A, Khoury DS, Schneider MD: A pivotal role for endogenous TGF-betaactivated kinase-1 in the LKB1/AMP-activated protein kinase energy-sensor pathway. Pro Natl Acad Sci USA 2006, 103:17378-17383.

26. Chung S, Yao H, Caito S, Hwang JW, Arunachalam G, Rahman I: Regulation of SIRT1 in cellular functions: role of polyphenols. Arch Biochem Biophys 2010, 501:79-90.

27. Hou X, Xu S, Maitland-Toolan KA, Sato K, Jiang B, Ido Y, Lan F, Walsh K, Wierzbicki M, Verbeuren TJ, Cohen RA, Zang M: SIRT1 regulates hepatocyte lipid metabolism through activating AMP-activated protein kinase. J Biol Chem 2008, 283:20015-20026.

28. Lin CL, Huang HC, Lin JK: Theaflavins attenuate hepatic lipid accumulation through activating AMPK in human HepG2 cells. J Lipid Res 2007, 48:2334-2343. 
29. Baas AF, Kuipers J, van der Wel NN, Batlle E, Koerten HK, Peters PJ, Clevers HC: Complete polarization of single intestinal epithelial cells upon activation of LKB1 by STRAD. Cell 2004, 116:457-466. 